\title{
Synthesis, Characterization and Antibacterial Activity of Zinc Oxide Nanoparticles
}

\author{
V. Keerthika, A. Ananth, M.R. Rajan* \\ Department of Biology, The Gandhigram Rural Institute (Deemed to be University), Gandhigram - 624 302, Tamil Nadu, India.
}

\section{ART IC LE DET A ILS}

\section{Article history:}

Received 04 July 2018

Accepted 14 July 2018

Available online 22 July 2018

\section{Keywords:}

Zinc Oxide Nanoparticles

Spectral Characterizations

Antibacterial Activity

\begin{abstract}
A B S T R A C T
Zinc oxide nanoparticles were synthesized by a chemical method and characterized by various analytical techniques such as UV-visible spectroscopy, SEM-EDX, XRD, and FTIR. X-ray diffraction and SEM analysis confirmed the formation of well- dispersed zinc oxide nanoparticles with average particle size $22 \mathrm{~nm}$ as well as revealed their spherical structure. Chemically synthesized nanoparticles were found to exhibit antibacterial activity against bacterial strains Escherichia coli, Pseudomonas aeruginosa and Staphylococcus aureus using agar well diffusion method of analysis.
\end{abstract}

\section{Introduction}

Nanotechnology is the technology to control a matter of an atomic and molecular scale. It has extraordinary potential to change the lives by improving existing products and enabling new ones. It facilitates the development of new materials in the $1-100 \mathrm{~nm}$ range, comparable to the size range of biological molecules and structures [1]. Nanoparticles are used as manipulation, sensing, and detection of biological structures and systems. The principal factors which make nanomaterials different from their bulk counterparts include an increase in their relative surface area and quantum effects, which affect their physical and chemical properties [2] and due to the high surface area to volume ratio, it develops as novel antimicrobial agents and flow enthusiasm to the researchers because of the developing microbial resistances against metal ions, anti-toxins and the development of resistant strains [3]. Due to the rapid development of nanotechnology, nanomaterials with various shapes and diameters have been prepared and used in some industrial products and commodities [46].

Among several nanoparticles, $\mathrm{ZnO}$ nanoparticles ( $\mathrm{n}-\mathrm{ZnO}$ ) have received more attention. Zinc oxide nanoparticles (ZnO-NPs) are common nanoparticles and widely used in many fields such as sunscreen products, cosmetics, pigments, industrial coatings, plastic additives, semiconductors, textiles, and antibacterial agents [7]. It also exhibits antibacterial activities when the particle is in the nanometer range, at that point ZnO Nps can connect with the bacterial surface as well as with the bacterial core, and consequently exhibits bactericidal components [8].

Due to numerous applications of nanoparticles, research on related to preparation and to know the properties of nanoparticles have become more attention in the past several years. Production of nanoparticles can be achieved through conventional chemical methods [9] and physical methods [10]. When comparing with physical method chemical method used for synthesizing the nanoparticles are simple and more effective. Furthermore, ZnO nanoparticles effectively resist microorganisms [11]. The work related to the antibacterial activity of $\mathrm{ZnO}$ nanoparticles against with three strains pathogenic bacteria such as Gram -ve Escherichia coli, Pseudomonas aeruginosa and Gram +ve Staphylococcus aureus is totally wanting. Hence the present study deals with synthesis of zinc oxide nanoparticles and its antibacterial activity.

\section{Experimental Methods}

Zinc acetate and sodium hydroxide were purchased from Nice chemicals, India. All the reagents used for the synthesis zinc oxide nanoparticles were analytical grade and used without further purification. All the glass wares were washed thrice with deionized water and dried before use.

\subsection{Synthesis of Zinc Oxide Nanoparticles}

Synthesis of zinc oxide nanoparticles was carried by simple precipitation method. For this study, $0.5 \mathrm{M}$ of zinc acetate $\left(\mathrm{Zn}\left(\mathrm{CH}_{3} \mathrm{COO}\right)_{2} .2 \mathrm{H}_{2} \mathrm{O}\right)$ was dissolved in $100 \mathrm{~mL}$ of distilled water and $1 \mathrm{M}$ of sodium hydroxide were also dissolved in $100 \mathrm{~mL}$ of distilled water. Precipitation was done by mixing of $1 \mathrm{M} \mathrm{NaOH}$ which is to be added in a dropwise to the $0.5 \mathrm{M}$ of zinc acetate solution under vigorous stirring. The process continued until the appearance of a milky white precipitate. During this precipitating process, $\mathrm{pH}$ was increased from 7 to 14 Following the precipitation, the solution was centrifuged at $3000 \mathrm{rpm}$ for $10 \mathrm{~min}$ and washed for several times with distilled water and ethanol to remove the by-products. The supernatant was then removed and the pellet was dried. After drying, the precipitate was calcined in a muffle furnace at $300{ }^{\circ} \mathrm{C}$ for $3 \mathrm{~h}$ and $\mathrm{ZnO}$ nanopowder was ground into fine powder.

\subsection{Characterization of Zinc Oxide Nanoparticles}

The chemically synthesized zinc oxide nanoparticles were characterized by UV-Vis spectroscopy using automated spectrometer Spectro UV-Vis double beam DUV 3500, scanning electron microscopy (SEM) using an LEO 1455 VP equipped with energy dispersive. The possible functional groups of $\mathrm{ZnO}$ Nps were analyzed by using Fourier transform infrared spectroscopy (FTIR) analysis with an instrument JASCO (FTIR-6200) spectrum. The X-ray diffraction was carried out by an X-ray diffractometer (Shimadzu XRD-6000, Japan) for the crystallographic structural analysis.

\subsection{Antibacterial Activity}

\subsubsection{Preparation of Inoculums}

One gram-positive Staphylococcus aureus and two gram-negative Escherichia coli, Pseudomonas aeruginosa bacterial strains were used for this study. Then the active cultures were prepared by transferring a loopful of culture from the stock to test tubes of nutrient broth that were incubated for $24 \mathrm{~h}$ at $37^{\circ} \mathrm{C}$ and used as inoculums for antibacterial activity. 


\subsubsection{Agar Well Diffusion Method}

Nutrient agar plates were swabbed on three axes with the sterile cotton-tipped swab, which was dipped in the freshly prepared diluted culture. Sterile cork borer was used to make the two $6 \mathrm{~mm}$ holes aseptically in the agar plate. ZnO Nps were prepared by diluting $10 \mathrm{mg}$ of dry ZnO Nps with $100 \mathrm{~mL}$ sterile distilled water and dispersed in water using ultrasonicator for 20 minutes. One hole was filled with ZnO Nps, one antibiotic disc and one well filled with distilled water which serves as a control. Then plates were incubated at $30^{\circ} \mathrm{C}$ for $24 \mathrm{~h}$. After incubation, the plates were observed for the zone of inhibition which was measured in terms of diameter.

\section{Results and Discussion}

\subsection{Synthesis of Zinc Oxide Nanoparticles}

As sodium hydroxide $(\mathrm{NaOH})$ was added to the zinc acetate $\left(\mathrm{Zn}\left(\mathrm{CH}_{3} \mathrm{COO}\right)_{2} \cdot 2 \mathrm{H}_{2} \mathrm{O}\right)$, it is found to be colour changes from colorless to milky white precipitate (Fig. 1) and this precipitate confirms the formation of zinc oxide nanoparticles.
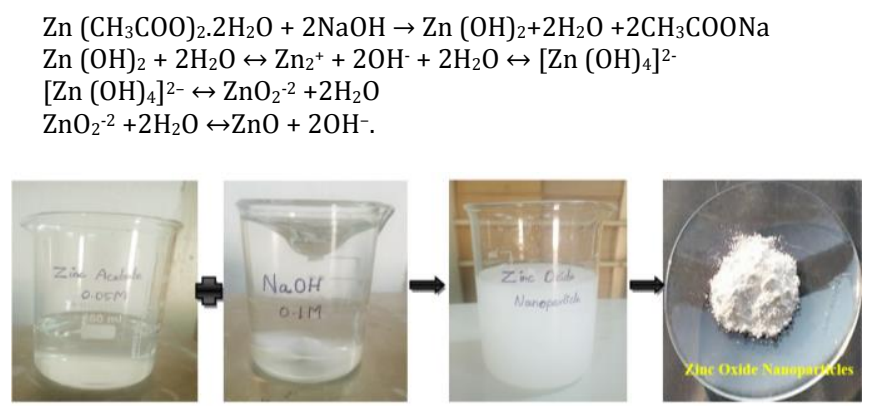

Fig. 1 Synthesis of Zinc Oxide Nanoparticles

\subsection{Characterization of Zinc Oxide Nanoparticles \\ 3.2.1 UV-Vis Analysis}

The primary characterization of chemically synthesized nanoparticles was done with UV-Vis spectroscopy which is a very useful and reliable technique. Zinc oxide Nps have unique optical properties which make them strongly interact with specific wavelengths of light. In addition, UVVIS spectroscopy is simple, easy, fast, required a short period of time for measurement, and to characterize the colloidal suspensions [12]. UV-Vis spectroscopy analysis of chemically synthesized ZnO Nps analyzed between the range $300-500 \mathrm{~nm}$ (Fig. 2) and showed high peak absorbance spectrum at $335 \mathrm{~nm}$. Satyanarayana et al. [13] also reported a peak at $320 \mathrm{~nm}$ for zinc oxide nanoparticles.

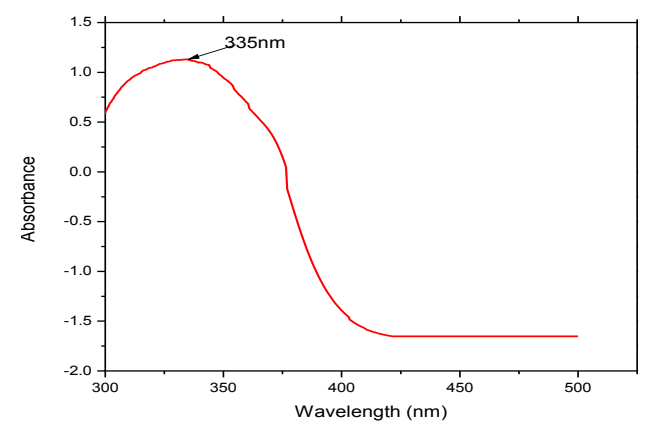

Fig. 2 UV-Vis analysis of zinc oxide nanoparticles

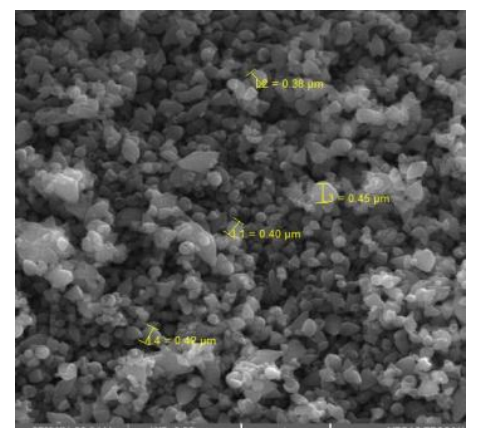

Fig. 3 SEM image of zinc oxide nanoparticles https://doi.org/10.30799/jnst.138.18040410

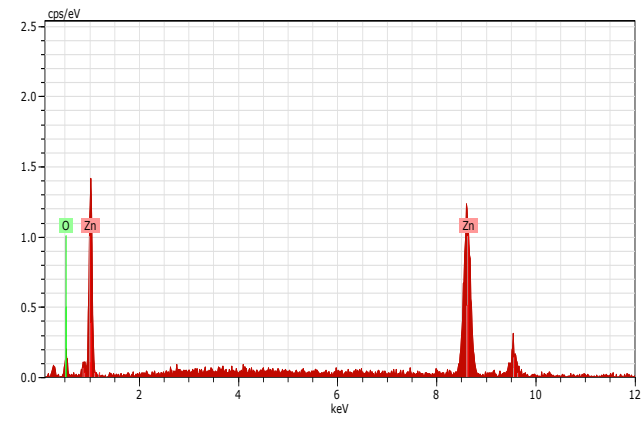

Fig. 4 EDAX analysis of zinc oxide nanoparticles

\subsubsection{SEM-EDAX Analysis}

SEM analysis was conducted in order to examine the morphology and structure of the chemically synthesized $\mathrm{ZnO}$ nanoparticles. This reveals that the obtained nanoparticles are uniform spherical in shape and shown in Fig. 3. It can be also used for predicting the antimicrobial activity of $\mathrm{ZnO}$ nanoparticles. Nie et al. [14] reported that the results from scanning electron microscopy indicated the presence of nanoparticles in growing medium may cause damages to the $E$. coli cell membrane. Fig. 4 indicates the high purity and chemical composition of $\mathrm{ZnO}$ nanoparticles which are confirmed by EDX analysis.

\subsubsection{X-Ray Diffraction Analysis (XRD)}

The crystalline structure of chemically synthesized zinc oxide nanoparticle was obtained using XRD. Dorofeey et al. [15] reported that XRD analysis is important and act as good potential techniques for nanostructures examination because it yields information about the substructure and sizes of crystallites of the materials. Fig. 5 shows that $\mathrm{ZnO}$ nanoparticle was highly crystalline and all diffraction peaks are well indexed $31.687^{\circ}, 34.339^{\circ}, 36.172^{\circ}, 47.453^{\circ}, 56.507^{\circ}, 62.768^{\circ}, 66.281^{\circ}$, $67.856^{\circ}, 68.981^{\circ}, 76.908^{\circ}, 92.670^{\circ}, 95.314^{\circ}$ and $98.472^{\circ}$ which corresponds to $100,002,101,102,110,103,200,112,201,202,210$, 211 and 114 crystal plane respectively (JCPDS 36-1451). Giri et al. [16] reported similar peaks for zinc oxide nanoparticle. The average crystalline size of $\mathrm{ZnO}$ nanoparticle is $22 \mathrm{~nm}$. The crystallite domain size of XRD peaks was calculated from the width of resulted peaks, confirming that they were free from non-uniform strains by adopting Scherrer's formula, $\mathrm{D}=0.94 \lambda / \beta \cos \theta$, where, $\mathrm{D}=$ average crystallite domain size, $\lambda=\mathrm{X}$-ray wavelength, $\beta=$ full width at half maximum (FWHM), and $\theta=$ diffraction angle.

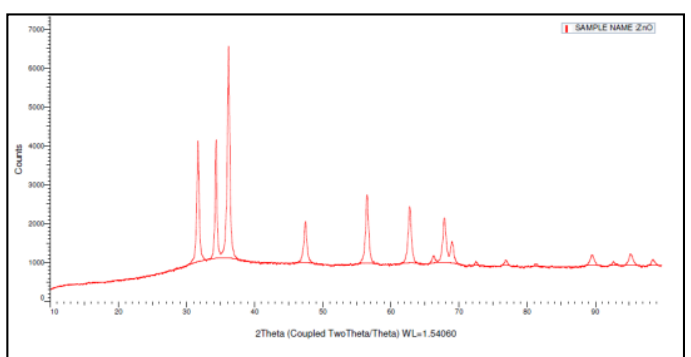

Fig. 5 XRD analysis of zinc oxide nanoparticle

\subsubsection{Fourier Transform Infrared Spectroscopy (FTIR)}

Fourier transform infrared spectroscopy (FTIR) is used to measure the vibration modes of functional groups of molecules and is sensitive to molecular structure, conformation, and environment. Therefore, in the current study, it is possible to directly relate the intensities of the absorption bands to the concentration of the corresponding functional groups. FTIR spectroscopy was analyzed in the range of $4000-400 \mathrm{~cm}^{-1}$. The FTIR spectra of chemically synthesized zinc oxide nanoparticles were analyzed for knowing the possible functional groups (Fig. 6). This FTIR spectrum shows the purity of $\mathrm{ZnO}$ nanoparticles, the peak at $402.0 \mathrm{~cm}^{-1}$ is the characteristic absorption of $\mathrm{Zn}-\mathrm{O}$ bond and the broad absorption peak at $3459.6 \mathrm{~cm}^{-1}$ can be attributed to the characteristic absorption of hydroxyl groups (Table 1). Similarly [17] reported that $\mathrm{ZnO}$ nanoparticles exhibit a rather broad and moderately strong band at $495 \mathrm{~cm}^{-1}$, owing to $\mathrm{Zn}-\mathrm{O}$ vibrational mode. The band at $3445 \mathrm{~cm}^{-1}$ corresponds to $\mathrm{O}-\mathrm{H}$ mode of adsorbed moisture in the annealed sample. The stretching $\mathrm{C}-\mathrm{O}$ vibration is observed at $1530 \mathrm{~cm}^{-1}$. The bands at 1625 and $2363 \mathrm{~cm}^{-1}$ are due to $\mathrm{C}=0$ and $\mathrm{CO}_{2}$ groups. Sharma et al. [18] applied the FTIR technique to characterize ZnO Nps and showed a standard peak of zinc oxide is around $464 \mathrm{~cm}^{-1}$. 


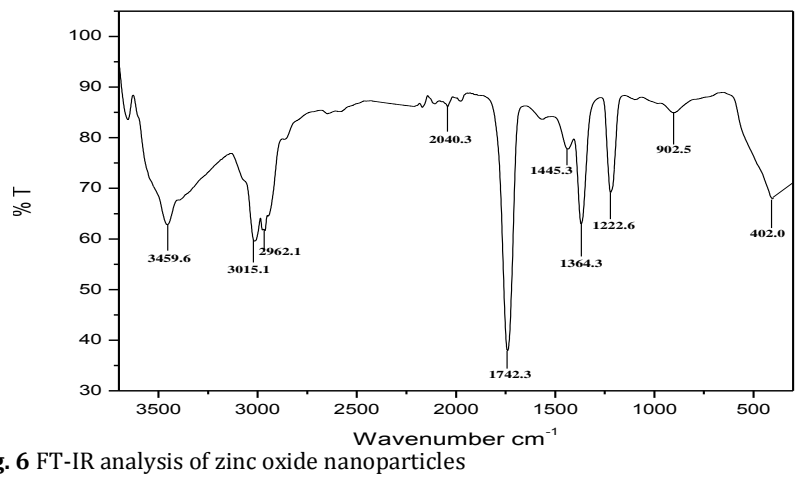

Fig. 6 FT-IR analysis of zinc oxide nanoparticles

Table 1 Functional group assignments of FT-IR characterization

\begin{tabular}{lll}
\hline S. No. & Wave number $\mathrm{ZnO} \mathrm{Nps}\left(\mathrm{Cm}^{-1}\right)$ & Spectral assignments \\
\hline 1 & 3459.6 & O-H Stretching vibration, broad \\
2 & 3015.1 & $=\mathrm{C}-\mathrm{H}$ Stretching vibration \\
3 & 2962.1 & $\mathrm{CH}_{3}$ and $\mathrm{CH}_{2}$ Stretching vibration \\
4 & 2040.3 & $\mathrm{CC}$ Stretching vibration \\
5 & 1742.3 & $\mathrm{C}=$ O Stretching vibration \\
6 & 1445.3 & $\mathrm{C}-\mathrm{O}$ Stretching mode, carbonate \\
7 & 1364.3 & $\mathrm{C}-\mathrm{H}$ bond bending \\
8 & 1222.6 & $\mathrm{C}-\mathrm{H}$ Deformation vibration \\
9 & 902.5 & $\mathrm{CH}$ Deformation vibration \\
10 & 402 & $\mathrm{Zn}-\mathrm{O}$ Stretching vibration, broad \\
\hline
\end{tabular}

Table 2 Antibacterial activity of $\mathrm{ZnO}$ Nps against pathogens

\begin{tabular}{lll}
\hline Pathogens & \multicolumn{2}{l}{ Zone of inhibition $(\mathrm{mm})$} \\
\cline { 2 - 3 } & ZnO Nps & Antibiotic \\
\hline Pseudomonas aeruginosa & 13 & 20 \\
Staphylococcus aureus & 15 & 22 \\
Escherichia coli & 10 & 18 \\
\hline
\end{tabular}

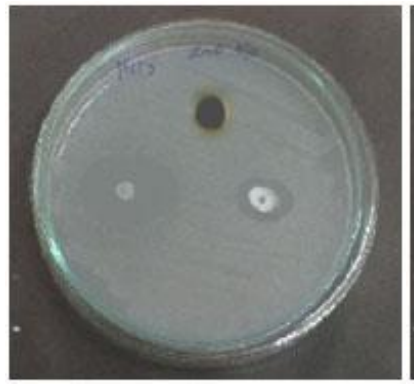

(a) Pseudomonas aeruginosa

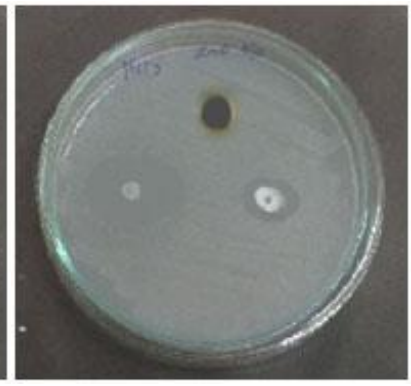

(b) Staphylococcus aureus

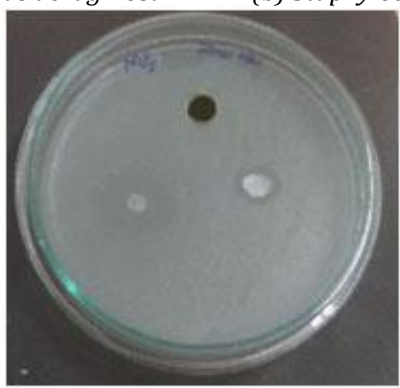

(c) Escherichia coli

A) Antibiotic B) ZnO Nps C) Control

Fig. 7 Zone of Inhibition of ZnO Nps against three bacterial strains

\subsection{Antibacterial Activity of Zinc Oxide Nanoparticles}

The antibacterial activity of chemically synthesized zinc oxide nanoparticles against three strains of pathogenic bacteria such as Escherichia coli, Pseudomonas aeruginosa, and Staphylococcus aureus was done by using well diffusion method. Antibacterial effect was measured by observing the zone of inhibition. The presence of an inhibition zone clearly indicated the antibacterial effect of $\mathrm{ZnO}$ nanoparticles as presented in Table 2. This assays revealed that the gram-negative bacteria are sensitive to the ZnO NPs, while it shows resistance to the synthetic antibiotic (Fig. 7). Sivakumar and Senthilkumar [19] observed the similar antibacterial activity of zinc oxide nanoparticles. Literature revealed that the electrostatic interactions between ZnO NPs and cell walls resulting in destroying bacterial cell integrity [20], the liberation of antimicrobial $\mathrm{Zn}^{2+}$ ions [21] which is related to an accumulation of ZnO NPs into the bacterial cells [22]. Mekala and Rajan [23] reported that $\mathrm{CuO}$ nanoparticles attach to the surface of the cell membrane disturbs its function and penetrates directly with the bacterial outer membrane and release $\mathrm{CuO}$ ions and smaller sized NPs can enter the mitochondria of cells through various pathways and thereby induce oxidative stress and cell death via apoptosis [24]. Thus ZnO NP may contort and harm bacterial cell layer, causing spillage of intracellular substance promoting cell death [25].

\section{Conclusion}

$\mathrm{ZnO}$ nanoparticles have been prepared using a wet chemical method. The structural characterization of synthesized nanoparticles are crystalline in structure and their diameter was around $22 \mathrm{~nm}$ confirmed by XRD. The synthesized ZnO nanoparticles exhibit the UV absorption peak at $335 \mathrm{~nm}$. In FT-IR spectroscopy pure ZnO nanoparticles show stretching vibrations at $402 \mathrm{~cm}^{-1}$. The chemically synthesized $\mathrm{ZnO} \mathrm{Nps}$ exhibit significant antibacterial activity against all the three bacterial strains, i.e., gram -ve E.coli, Pseudomonas aeruginosa and gram +ve bacteria Staphylococcus aureus and show a significant zone of inhibition to $\mathrm{ZnO}$ Nps compared to the positive control penicillin. This study proves that zinc oxide nanoparticles possess good antibacterial activity.

\section{References}

[1] S.E. McNeil, Nanotechnlogy for the biologist, J. Leuk. Bio. 78 (2005) 585-594.

[2] A. Nel, T. Xia, L. Madler, N. Li, Toxic potential of materials at the nanolevel, Sci. 311 (2006) 622-626

[3] Ho Chan, Ming-HsunTsai, Synthesis and characterization of $\mathrm{ZnO}$ nanoparticles having prism shape by a novel gas condensation process, Rev. Adv. Mater. Sci. 18 (2008) 734-743

[4] D.Y.Joh, J. Kinder, L.H. Herman, S.Y. Ju, M.A. Segal, J.N. Johnson, K.L. Chan Garnet J. Park, Single-walled carbon nanotubes as excitonic optical wires, Nat. Nanotechol. 6 (2011) 51-56.

[5] F. Tang, L. Li, D. Chen, Mesoporous silica nanoparticles: Synthesis biocompatibility and drug delivery, Adv. Mater. 24 (2012)1504-1534

[6] S. Laurent, D. Forge, M. Port, A. Roch, C. Robic, L. Van der Elst, R.N. Muller, Magnetic iron oxide nanoparticles: synthesis, stabilization, vectorization, physico-chemical characterizations and biological applications, Chem. Rev. 108 (2008) 2064-2110.

[7] J.H. Li, X.R. Liu, Y. Zhang, F.F. Tian, G.Y. Zhao, Q.L.Y. Yu, F. L. Jiang, Y. Liu, Toxicity of nano zinc oxide to mitochondria, Toxicol. Rev. 1(2) (2012) 137-144.

[8] J.T. Seil, T.J. Webster, Antimicrobial applications of nanotechnology: methods and literature, Int. J. Nanomed. 7 (2012) 2767-2781.

[9] C.B. Murray, C.R. Kangan, M.G. Bawendi, Synthesis and characterization of monodisperse nanocrystals and close-packed nanocrystal assemblies, Annu. Rev. Mater. Sci. 30 (2000) 545-610.

[10] P. Ayyub, R. Chandran, R.P. Taneja, A. Sharma, R. Pinto, Synthesis of nanocrystalline materials by sputtering and laser ablation at low temperature, Appl. Phys. A 73 (2001) 67-70.

[11] P. Nagarajan, R. Vijayaraghavan, Enhanced bioactivity of $\mathrm{ZnO} \mathrm{nps}$ an antimicrobial study, Sci. Tech. Adv. Mat. 89 (2008) 1-7.

[12] E. Tomaszewska, K. Soliwoda, K. Kadziola, G. Celichowski, M. Cichomski, W. Szmaja, J. Grobelny, Detection limits of DLS and UV-vis spectroscopy in characterization of polydisperse nanoparticles colloids, J. Nanomater. 31 (2013) 3081-1-10.

[13] S. Talam, S.R. Karumuri, N. Gunnam, Synthesis, characterization and spectroscopic properties of ZnO nanoparticles, ISRN Nanotech. 372505 (2012) $1-6$.

[14] L. Nie, L. Gao, X. Yan, T. Wang, Functionalized tetrapod-like ZnO nanostructures for plasmid DNA purification, polymerase chain reaction and delivery, Nanotech. 18 (2007) 015101-1-6.

[15] G.A. Dorofeey, A.N. Streletskii, I.V. Povstugar, A.V. Protasov, E.P. Elsukov Determination of nanoparticle sizes by X-ray diffraction, Colloid J. 74 (2012) 675-685.

[16] P.K. Giri, S. Bhattacharyya, D.K. Singh, R. Kesava-moorthy, B.K. Panigrahi, K.G.M. Nair, Correlation between microstructure and optical properties of $\mathrm{ZnO}$ nanoparticles synthesized by ballmiling, J. Appl. Phy. 102(9) (2007) 1-8.

[17] K. Chitra, G. Annadurai, Antimicrobial activity of wet chemically engineered spherical shaped $\mathrm{ZnO}$ nanoparticles on food borne pathogen, Int. Food Res. J. 20(1) (2013) 59-64.

[18] D. Sharma, J. Rajput, B. Kaith, M. Kaur, S.S. Sharma, Synthesis of ZnO nanoparticles and study of their antibacterial and antifungal properties, Thin Soil Films 519 (2010) 1224-1229.

[19] T. Sivakumar, S.R. Senthilkumar, Green tea (Camellia sinensis) mediated synthesis of zinc oxide $(\mathrm{ZnO})$ nanoparticles and studies on their antimicrobial activities, Int. J. Pharm. Sci. 6(6) (2014) 461-465.

[20] L.K. Adams, D.Y. Lyon, P.J. Alvarez, Comparative eco-toxicity of nanoscale $\mathrm{TiO}_{2}$, $\mathrm{SiO}_{2}$, and $\mathrm{ZnO}$ water suspensions, Water Res. 40(19) (2015) 3527-3532.

[21] K. Kasemets, A. Ivask, H.C. Dubourguier, A. Kahru, Toxicity of nanoparticles of $\mathrm{ZnO}, \mathrm{CuO}$ and $\mathrm{TiO}_{2}$ to yeast Saccharomyces cerevisiae, Toxicol. In-Vitro 23 (2009) 1116- 1122 . 
[22] R. Brayner, R. Ferrari-lliou, N. Brivois, S. Djediat, M.F. Benedetti, F. Fie, Toxicological impact studies based on Escherichia coli bacterial in ultrafine $\mathrm{ZnO}$ nanoparticles colloidal medium, Nano Lett. 6 (2006) 866-870.

[23] J. Mekala, M.R. Rajan, Green synthesis of copper oxide nanoparticles using aqueous wilayati thulsi (Hyptis suveolens) extract- characterization and study of antibacterial effects, Int. J Cur. Res. 8(10) (2016) 39655-39661.
[24] T. Xia, M. Kovochich, A.E. Nel, Impairment of mitochondrial function by particulate matter (PM) and their toxic components: implications for PMinduced cardiovascular and lung disease, Front. Biosci. 12 (2007) 1238-1246.

[25] Y. Liu, L. He, A. Mustapha, H. Hu, Z.Q. Li, M. Lin, Antibacterial activities of zinc oxide nanoparticles against Escherichia coli 0157:H7, J. Appl. Microbiol. 107 (2009) 1193-1201. 